\title{
Correction: A Novel Narrative E-Writing Intervention for Parents of Children With Chronic Life-Threatening Illnesses: Protocol for a Pilot, Open-Label Randomized Controlled Trial
}

Andy Hau Yan $\mathrm{Ho}^{1,2,3}$, PhD, EdD, MSocSc, PGDE, BA; Oindrila Dutta ${ }^{1}$, BA, MA; Geraldine Tan-Ho ${ }^{1}$, MSocSc; Toh Hsiang Benny Tan ${ }^{4}$, BEng, MSc; Xinyi Casuarine Low ${ }^{1}$, BSc, MSc; Sashikumar Ganapathy ${ }^{5}$, MBBS; Josip Car ${ }^{6}$, MSc, PhD, PGDE, MBBS; Ringo Moon-Ho Ho ${ }^{1}$, BSocSc, MSc, PhD; Chun Yan Miao ${ }^{4}$, BSc, MEng, PhD

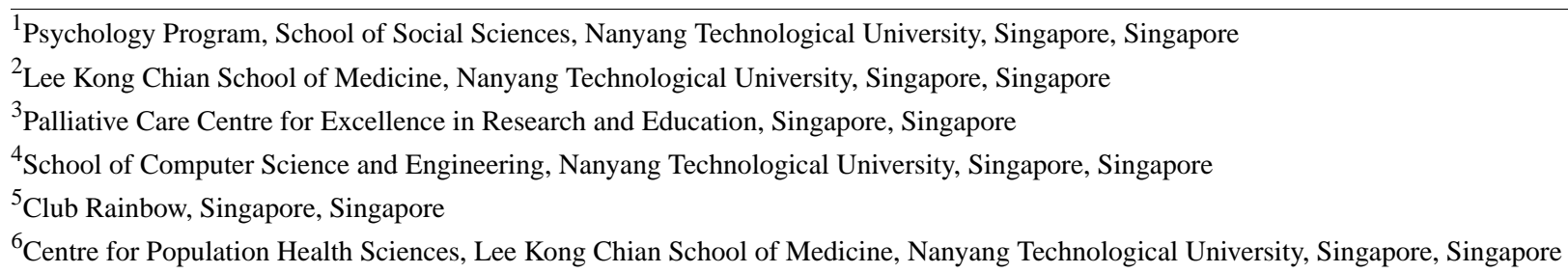

\section{Corresponding Author:}

Andy Hau Yan Ho, PhD, EdD, MSocSc, PGDE, BA

Psychology Program

School of Social Sciences

Nanyang Technological University

48 Nanyang Avenue

SHHKB-04-03

Singapore, 639818

Singapore

Phone: 6563168943

Email: andyhyho@ntu.edu.sg

\section{Related Article:}

Correction of: https://www.researchprotocols.org/2020/7/e17561/

(JMIR Res Protoc 2020;9(8):e22286) doi: 10.2196/22286

In "A Novel Narrative E-Writing Intervention for Parents of Children With Chronic Life-Threatening Illnesses: Protocol for a Pilot, Open-Label Randomized Controlled Trial" (JMIR Res Protoc 2020;9(7):e17561) the authors noted several errors.

In the original paper, an incorrect telephone number was provided for the corresponding author. The telephone number has been corrected to 6563168943 .
One of the author names was incorrectly displayed as "Casuarine Xinyi Low". It has now been corrected to:

\section{Xinyi Casuarine Low}

The correction will appear in the online version of the paper on the JMIR Publications website on August 18, 2020, together with the publication of this correction notice. Because this was made after submission to PubMed, PubMed Central, and other full-text repositories, the corrected article has also been resubmitted to those repositories.

This is a non-peer-reviewed article. Submitted 07.07.20; accepted 07.07.20; published 18.08.20.

Please cite as:

Ho AHY, Dutta O, Tan-Ho G, Tan THB, Low XC, Ganapathy S, Car J, Ho RMH, Miao CY

Correction: A Novel Narrative E-Writing Intervention for Parents of Children With Chronic Life-Threatening Illnesses: Protocol for

a Pilot, Open-Label Randomized Controlled Trial

JMIR Res Protoc 2020;9(8):e22286

URL: https://www.researchprotocols.org/2020/8/e22286

doi: $\underline{10.2196 / 22286}$

PMID: $\underline{32809950}$ 
(C)Andy Hau Yan Ho, Oindrila Dutta, Geraldine Tan-Ho, Toh Hsiang Benny Tan, Xinyi Casuarine Low, Sashikumar Ganapathy, Josip Car, Ringo Moon-Ho Ho, Chun Yan Miao. Originally published in JMIR Research Protocols (http://www.researchprotocols.org), 18.08.2020. This is an open-access article distributed under the terms of the Creative Commons Attribution License (https://creativecommons.org/licenses/by/4.0/), which permits unrestricted use, distribution, and reproduction in any medium, provided the original work, first published in JMIR Research Protocols, is properly cited. The complete bibliographic information, a link to the original publication on http://www.researchprotocols.org, as well as this copyright and license information must be included. 